Article

\title{
Modeling of Selected Lighting Parameters of LED Panel
}

\author{
Krzysztof Baran ${ }^{1, *}$, Antoni Różowicz ${ }^{2}$, Henryk Wachta ${ }^{1}$ and Sebastian Różowicz ${ }^{2}$ \\ 1 Department of Power Electronics and Power Engineering, Rzeszow University of Technology, \\ Wincentego Pola 2, 35-959 Rzeszow, Poland; hwachta@prz.edu.pl \\ 2 Department of Industrial Electrical Engineering and Automatic Control, Kielce University of Technology, \\ 7 Tysiąclecia Państwa Polskiego Str., 25-314 Kielce, Poland; rozowicz@tu.kielce.pl (A.R.); \\ s.rozowicz@tu.kielce.pl (S.R.) \\ * Correspondence: kbaran@prz.edu.pl; Tel.: +48-17-865-19-77
}

Received: 1 June 2020; Accepted: 10 July 2020; Published: 11 July 2020

check for updates

\begin{abstract}
Semiconductor light sources are currently the fastest growing and most energy efficient group of light sources used in lighting technology. Their lighting parameters, such as luminous flux, correlated color temperature and color rendering index depend on the value of the forward current, as well as the temperature of the junction. LED source manufacturers usually specify, in data sheets, the effect of junction temperature and forward current on the luminous flux for individual light sources. The difficulty, however, is the correct determination of temperature and then lighting parameters, by simulation methods for multi-source lighting systems. Determining the junction temperature which affects lighting parameters is particulary important in the case of LED panels and luminaires, where thermally coupled LED sources shaping the output lighting parameters are in close proximity to each other. Additionally, other factors influencing the temperature distribution of sources, such as the design and geometry of the cooling system, the design of the printed circuit and thermal interface material used, should be considered. The article is a continuation of the publication in this journal where the influence of factors influencing the temperature distribution of the LED panel is presented. The purpose of the research in this article was to confirm the possibility of using CFD (Computational Fluid Dynamics) software, as well as to determine the accuracy of the results obtained in the temperature analysis of the multi-source LED panel, and in determining the output lighting parameters of the LED panel based on it. In this article, based on previously published research, a LED panel model with a cooling system was made, and then the CFD software determined the junction temperature of all light sources. The determined temperature of the LED sources constituted the basis for determining the output lighting parameters of the panel: luminous flux, color temperature and color rendering index. The simulation results were verified by real measurements on the constructed LED panel prototype. The LED panel temperature difference between the simulation results and the real results on the prototype did not exceed $5 \%$. Moreover, the error of lighting parameters between the simulation results obtained and the results on the LED panel prototype in the worst case was $4.36 \%$, which proves the validity and accuracy of simulation studies.
\end{abstract}

Keywords: LED panel; lighting parameters; junction temperature; thermal modeling; CFD

\section{Introduction}

The dynamic development of semiconductor light sources has made them dominant in lighting technology, displacing the previously used discharge light sources. Increasingly higher values of luminous efficiency mean that LEDs (light-emitting diode) are currently the most energy-efficient group of light sources [1-3]. LED light sources are also equipped with advanced lens optics, in order to 
obtain the maximum amount of LED light transmitted by the optical system for the purpose of energy savings, savings in terms of energy consumption, and the cost of electricity bills [4,5]. Electrical light sources are responsible for an energy consumption of around 1/6 to $1 / 5$ of the worldwide electricity production, and the use of semiconductor light sources reduces energy consumption and significantly reduces carbon dioxide emissions into the atmosphere $[5,6]$.

In luminaires where a high luminous flux value is required, and therefore a high luminaire power-from several dozen to several hundred Watts (road, industrial or illumination lighting) — high-power LED sources are most often used. Individual sources are characterized by a power of several Watts, so to obtain the required luminous flux $\Phi$, the sources are grouped close to one another, forming panels containing from several to several hundred LEDs [7-13].

The main limitations of an even faster development of semiconductor light sources are thermal problems and the high temperature of the semiconductor junction $T_{j}$. Only a small part of the power supplied to the LED sources is converted into luminous flux $\Phi$, while the remaining part is lost in the form of heat $[14,15]$. According to most scientific publications, the optical efficiency of LED sources is $30 \%$, which means that $70 \%$ of the power is heat loss [16-21]. In a small number of publications, the research results indicate that, for the latest LED sources, the above value of optical efficiency may be higher [22,23]. In addition, the increasingly higher power of LED sources and the small chip area result in high values of thermal density and obstruct effective heat abstraction to the environment. The mentioned thermal problems are more applicable to LED panels, where many sources located in close proximity to one another interact thermally, causing the rise of junction temperature $T_{j}$ in individual sources.

To limit the junction temperature $T_{j}$, cooling systems ensuring effective heat abstraction are used. Among the solutions currently available on the market, passive systems, in which natural convection is the basic heat exchange mechanism, are most commonly used in LED sources [24-26]. The decrease of junction temperature $T_{j}$ prolongs the lifetime of the sources and results in higher values of light efficiency. The basic lighting parameters, such as luminous flux $\Phi$, color temperature $C C T$ (correlated color temperature) and $C R I$ (color rendering index), depend on the junction temperature $T_{j}[14,27]$. An example graph, illustrating the correlation between junction temperature, electrical and light parameters, is presented in Figure 1.

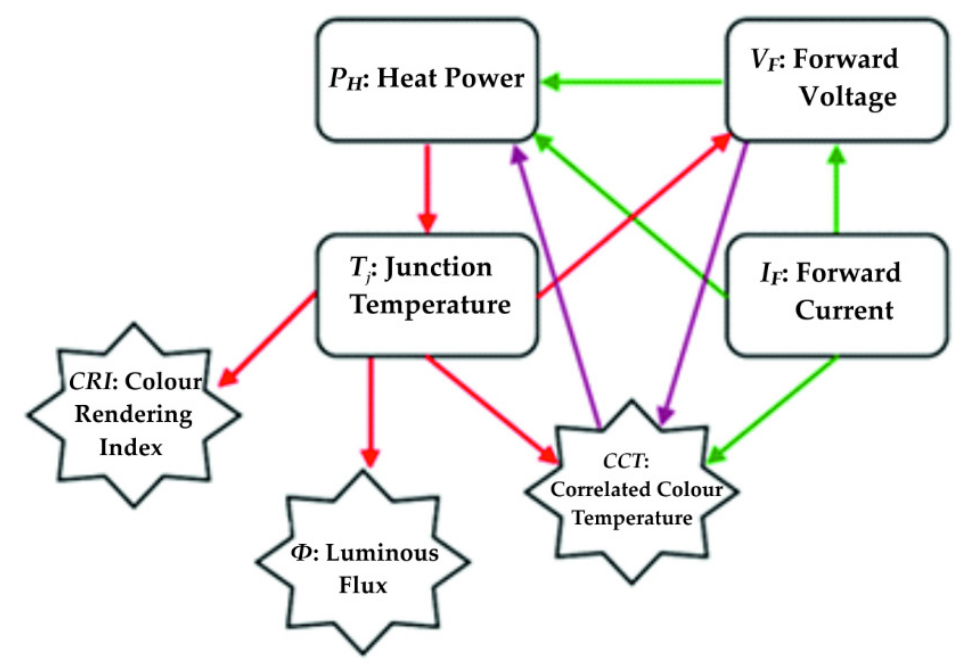

Figure 1. Relationships between junction temperatures $T_{j}$, lighting parameters, and electrical parameters. 
The current-voltage characteristic of LED sources, which affects the lighting parameters of LED sources, strongly depends on the junction temperature. The change in forward voltage $V_{F}$ as a function of junction temperature $T_{j}$ is described by the relationship [14]:

$$
\frac{d V_{F}}{d T_{j}}=\frac{V_{F}}{T_{j}}-\frac{V_{G 0}+m \cdot l \cdot V_{T}}{T_{j}}
$$

where: $T_{j}$ - junction temperature, $l-$ is the power factor in the temperature dependence, $V_{G 0}-$ nominal value of the bandgap voltage of the semiconductor material, $m$-constant ( $m=1$ for ideal diode), $V_{T}$-thermal voltage (roughly $26 \mathrm{mV}$ around room temperature $300 \mathrm{~K}$ ).

For single LED sources, the voltage $V_{F}$ change as a function of junction temperature $T_{j}$ is -1 to $-3 \mathrm{mV} /{ }^{\circ} \mathrm{C}$, and is called the temperature sensitivity of the forward voltage.

A change in the junction temperature also changes the lighting parameters. The change of luminous flux $\Phi$, as a function of junction temperature $T_{j}$, according to photo-electro-thermal theory, is described by the relationship [28]:

$$
\varnothing=E_{0} \cdot\left[1+k_{e}\left(T_{j}-T_{0}\right)\right] \cdot P_{e}
$$

where: $E_{0}$-the luminous efficacy at $25{ }^{\circ} \mathrm{C}, k_{e}$-negative coefficient representing the rate of reduction of the luminous efficacy with junction temperature, $T_{j}$ - junction temperature, $T_{0}-25^{\circ} \mathrm{C}$, $P_{e}$-electrical power.

As with luminous flux, a change in junction temperature affects colorimetric values, such as color temperature $C C T$ and color rendering index CRI. The effect of temperature is more significant in the case of LED sources, in which white color is created using a source of blue and yellow phosphor. A change in the junction temperature value causes a change in the spectrum of the LED source, which results in a change in CCT and CRI. As the temperature of the junction increases, as the electric power increases, the influence of temperature on the energy gap begins to dominate, and the peak wavelength shifts linearly towards longer waves. The above relationship can be described as follows [28]:

$$
\lambda_{\text {peak }}\left(P_{e}, T_{j}\right)=a \cdot\left(T_{j}\right) \cdot P_{e}^{2}-b \cdot\left(T_{j}\right) \cdot P_{e}+\beta_{\text {peak } \_b}
$$

where: $\beta_{\text {peak }} b$ - the referenced $\lambda_{\text {peak }}$ peak wavelength of the blue spectrum at ambient temperature, $a$ and $b$-positive coefficients dependent on the junction temperature, $T_{j}$-junction temperature, $P_{e}$ - electrical power.

In the literature, the number of publications related to the effect of temperature on the lighting parameters of LED sources is relatively small, and the focus is mainly laid on studies of individual LED sources. There is a lack of literature in which thermal analysis of luminaires with complex geometry is presented, where the junction temperature of individual sources is not a simple relationship based on superposition. There is also a lack of literature positions in which the determined junction temperature is the basis for determining the lighting parameters of the multi-source LED panel, and not the single light source itself.

The literature $[29,30]$ presents thermal studies on the impact of the heat sink design on the temperature distribution of high-power electronic systems, e.g., high-power LED sources and CPU. In [31,32], the temperature distribution of LED sources was examined depending on the distance and shape of the heat sink fins. In the article [23], in addition to the heat sink design, the effect of the printed circuit used was examined. The effect of forced and free convection on the temperature of LED sources was also studied. In [33], the performance of a conventional heat sink with fins were compared in relation to the heat sink, in which optimized fins with additional holes were used. In the literature [34], the effect of heat sink orientation on convective air flow and temperature distribution was examined. Various heat sink designs and different materials in the LED bulb design have been studied to increase the efficiency of natural convection and improve heat dissipation [35]. A simplified method of thermal analysis of LED sources is the use of compact thermal models (CTM), which usually consist of a very limited number of thermal capacitors and resistors, ensuring satisfactory simulation accuracy. Thermal 
tests can be carried out in this case using SPICE simulators [36,37]. Unfortunately, ladder models are not independent of boundary conditions, and can only be used at a specific LED operating point and cooling conditions. Currently, research is underway on complex compact multi-domain models that will take into account the interrelationships between multiple LEDs contained in a single luminaire, for example the Delphi4LED European project $[38,39]$. As of today, however, there is a small number of available research results on the formation of output lighting parameters obtained, on the basis of a complex three-dimensional thermal analysis of multi-source lighting systems.

The modeling method links the heat sink geometrical parameters, as well as the optical, electrical and thermal properties presented in the article [40]. However, the analytical model presented concerned simple heat sink geometry, where a single LED source was included in the analysis and only the luminous flux $\Phi$ was considered. The thermal analysis for a single LED source and the effect of temperature on the luminous flux $\Phi$ are presented in the article [41], where CFD (Computational Fluid Dynamics) Comsol software was used for the calculations.

The articles listed above mainly concern modeling of cooling systems for effective heat removal from a semiconductor junction. The number of publications in which the resulting temperature distribution with light parameters is associated is relatively small, and the available test results mainly concern individual LED sources.

This article is a continuation of research published in this journal regarding the influence of factors influencing the temperature distribution of the LED panel [23]. This paper deals with the results of the study on modeling the lighting parameters (luminous flux $\Phi$, color temperature and color rendering index) for the LED panel developed on the basis of previous research results [23]. The effect of temperature on the above lighting parameters was determined experimentally for a single LED source on which the LED panel construction was based. The thermal power of the source $P_{H}$ used in the construction of the thermal model of LED panel was also determined. The determined thermal model of the panel and the temperature distributions obtained on its basis for three values of forward current $I_{F}$ provided the basis for determining the final lighting parameters of the tested LED panel. The simulation results were verified by real tests conducted on a prototype.

\section{Results of Studies}

\subsection{The Effect of Junction Temperature on the Lighting Parameters of a Single LED Source}

The starting point for the studies related to modeling the lighting parameters of LED panel was to determine the effect of junction temperature $T_{j}$ on the lighting parameters of a single light source. One of the most efficient high-power LED sources available on the market was selected for our studies. The LED source was soldered to a printed circuit board with metal core (MCPCB) with dimensions of $25 \times 25 \times 1.6 \mathrm{~mm}$.

The tests were carried out on a GL Optic measuring stand, which included an integrating sphere (GL Opti Sphere) with a diameter of $500 \mathrm{~mm}$ [42], a GL Spectis 6.0 spectrometer [43], a programmable DC power supply TDK-Lambda GENH300-2.5, and a Peltier module with a 5305 TECSource temperature controller, manufactured by Arroyo Instruments. The accuracy of the temperature measurement of the Peltier module was $0.4{ }^{\circ} \mathrm{C}$, and was the sum of the accuracy of the temperature monitor and thermocouple [44].

The tested LED source, characteristic temperatures and measuring stand are presented in Figure 2. 


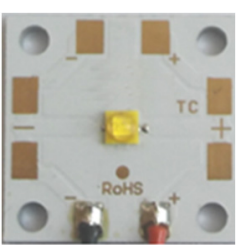

(a)

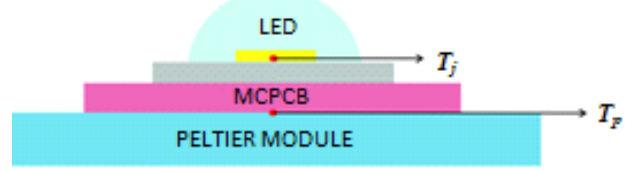

(b)

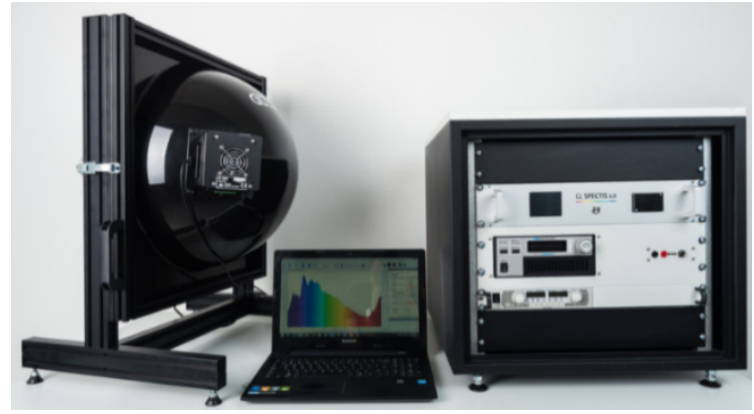

(c)

Figure 2. The studied LED source (a), characteristic temperatures (b) and test stand of the GL Optic Company (c).

The semiconductor light source selected for testing was installed on the surface of a Peltier module (Figure $2 b$ ), on which temperature $T_{p}$ was set. The measurements were carried out for four temperatures $T_{p}: 25 ; 45 ; 65 ; 85^{\circ} \mathrm{C}$, and for three values of forward currents $I_{F}: 350 ; 700$ and $1050 \mathrm{~mA}$.

In order to transform the temperature of the Peltier module $T_{p}$ into the junction temperature $T_{j}$, the thermal resistance of the MCPCB substrate and the thermal resistance between the junction and case of the tested LED source should be additionally considered, according to the equation:

$$
T_{j}=T_{p}+\left(R t h_{M C P C B}+R t h_{j-c}\right) \cdot P_{H}
$$

where: $T_{j}$-junction temperature, $T_{p}$-Peltier module temperature, $R t h_{M C P C B}-\mathrm{MCPCB}$ thermal resistance, $R t_{j-c}-$ LED source thermal resistance junction to case and $P_{H}$-heat power.

The value of thermal power $P_{H}$ for the LED source was determined experimentally and presented in Table 1. The value of resistance $R t h_{j-c}$ is discussed in Section 2.2 of this article and presented in Table 2, while the thermal resistance of the $\mathrm{MCPCB}$ substrate was $0.45^{\circ} \mathrm{C} / \mathrm{W}$, and this constituted a negligible part of the total thermal resistance.

Table 1. Electric power $P_{e}$, optical power $P_{o}$, heat power $P_{H}$ and optical efficiency $\eta_{o}$ for the studied LED source.

\begin{tabular}{cccccc}
\hline Current $\boldsymbol{I}_{\boldsymbol{F}}(\mathbf{m A})$ & $\begin{array}{c}\text { Temperature } \\
\boldsymbol{T}_{\boldsymbol{p}}\left({ }^{\circ} \mathbf{C}\right)\end{array}$ & $\begin{array}{c}\text { Electrical } \\
\text { Power } \boldsymbol{P}_{\boldsymbol{e}}(\mathbf{W})\end{array}$ & $\begin{array}{c}\text { Optical Power } \\
\boldsymbol{P}_{\boldsymbol{o}}(\mathbf{W})\end{array}$ & Heat Power $\boldsymbol{P}_{\boldsymbol{H}}(\mathbf{W})$ & $\begin{array}{c}\text { Optical } \\
\text { Efficiency } \boldsymbol{\eta}_{\boldsymbol{o}}(\boldsymbol{\%})\end{array}$ \\
\hline \multirow{4}{*}{350} & 25 & 1.01 & 0.50 & 0.51 & 49.83 \\
& 45 & 0.99 & 0.49 & 0.50 & 49.39 \\
& 65 & 0.98 & 0.48 & 0.50 & 48.69 \\
& 85 & 0.97 & 0.46 & 0.51 & 47.70 \\
\hline \multirow{3}{*}{700} & 25 & 2.13 & 0.94 & 1.19 & 43.92 \\
& 45 & 2.10 & 0.91 & 1.19 & 43.36 \\
& 65 & 2.08 & 0.88 & 1.20 & 41.52 \\
\hline \multirow{3}{*}{1050} & 85 & 2.06 & 0.85 & 1.18 & 39.62 \\
& 25 & 3.35 & 1.33 & 2.02 & 38.94 \\
& 45 & 3.30 & 1.29 & 2.01 & 38.09 \\
\hline
\end{tabular}

Figure 3 shows the changes in luminous flux $\Phi, C C T$ and $C R I$, as a function of Peltier module temperature $T_{p}$ and transformed junction temperature $T_{j}$.

The increase of temperature $T_{p}$ set on the Peltier module, and the consequent increase of temperature of the junction $T_{j}$ caused the change of lighting parameters for all three tested forward currents $I_{F}$. The increase of temperature by $60^{\circ} \mathrm{C}$ caused a linear decrease of the luminous flux $\Phi$ value. The decrease was $9 \%$ for $I_{F}=350 \mathrm{~mA}$ and $11 \%$ for $I_{F}=700$ and $1050 \mathrm{~mA}$. 
The obtained test results (Figure $3 b$ ) indicate that the color temperature of CCT depends on the value of the forward current $I_{F}$ and the temperature. The increase of forward current $I_{F}$ caused an increase of color temperature CCT. At $I_{F}=350 \mathrm{~mA}$ and $T_{p}=25{ }^{\circ} \mathrm{C}$, the CCT temperature was $4853 \mathrm{~K}$, and at $I_{F}=1050 \mathrm{~mA}$, it increased to $4953 \mathrm{~K}$. For the tested forward currents $I_{F}$, the increase of temperature $T_{p}$ on the Peltier module from 25 to $85^{\circ} \mathrm{C}$ resulted in the rise of color temperature CCT by about $70 \mathrm{~K}$.

In the case of color rendering index $C R I$, no significant effect of forward current $I_{F}$ on its value was noticed. The temperature increase resulted in a linear increase of the $C R I$ index, where a $60{ }^{\circ} \mathrm{C}$ increase caused an increase of $C R I$ from 70.2 to 71.6 , and for current $I_{F}=350 \mathrm{~mA}$, this value was slightly higher.

The graphs of the luminous flux $\Phi$ change and the color rendering index $C R I$ as a function of junction temperature $T_{j}$ were approximated by the equations of a linear function, while the graph of correlated color temperature CCT was approximated by the equation of a quadratic function (Figure 3). The determined equations will be used to determine the lighting parameters $(\Phi, C C T, C R I)$ of the modeled panel with many LED sources (Section 2.3).

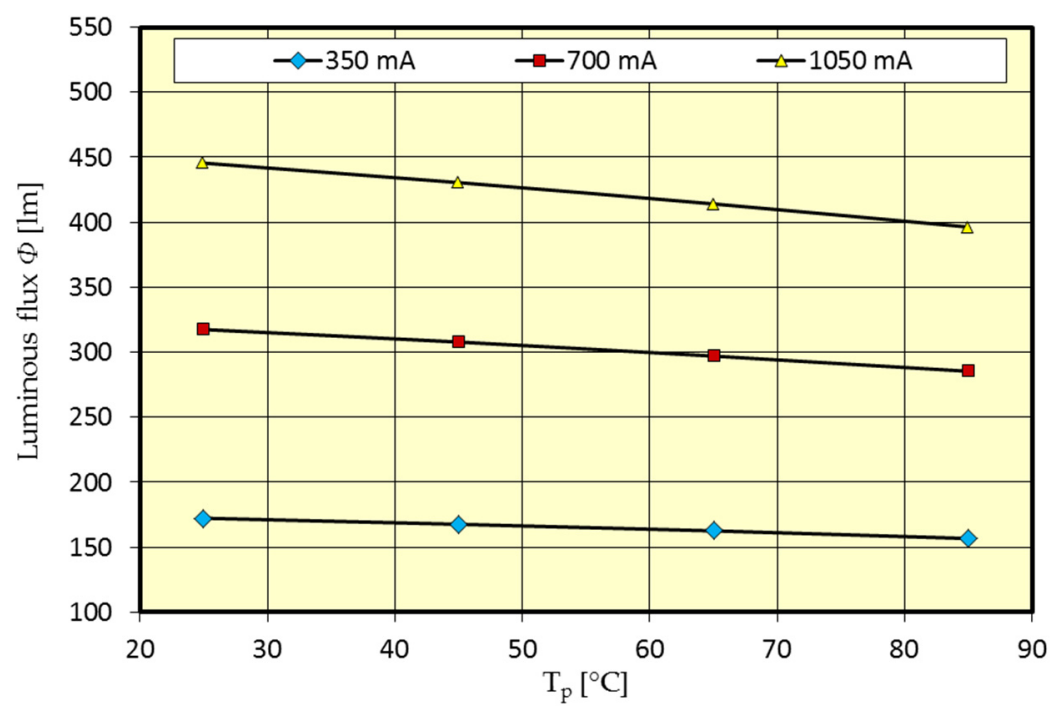

(a)

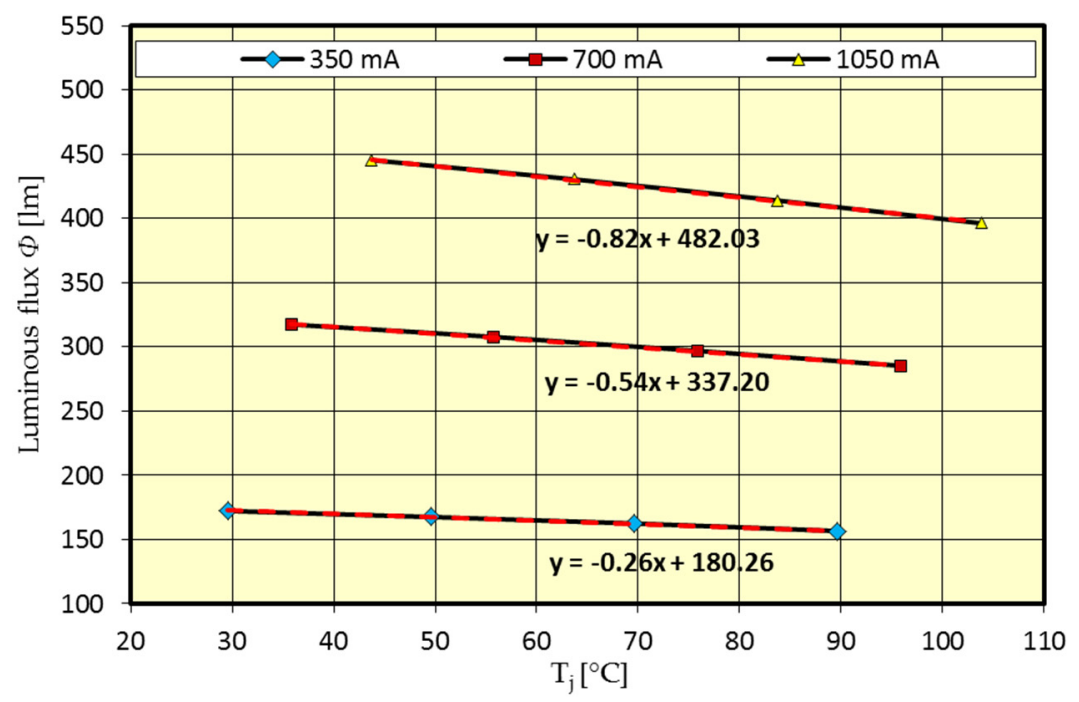

Figure 3. Cont. 


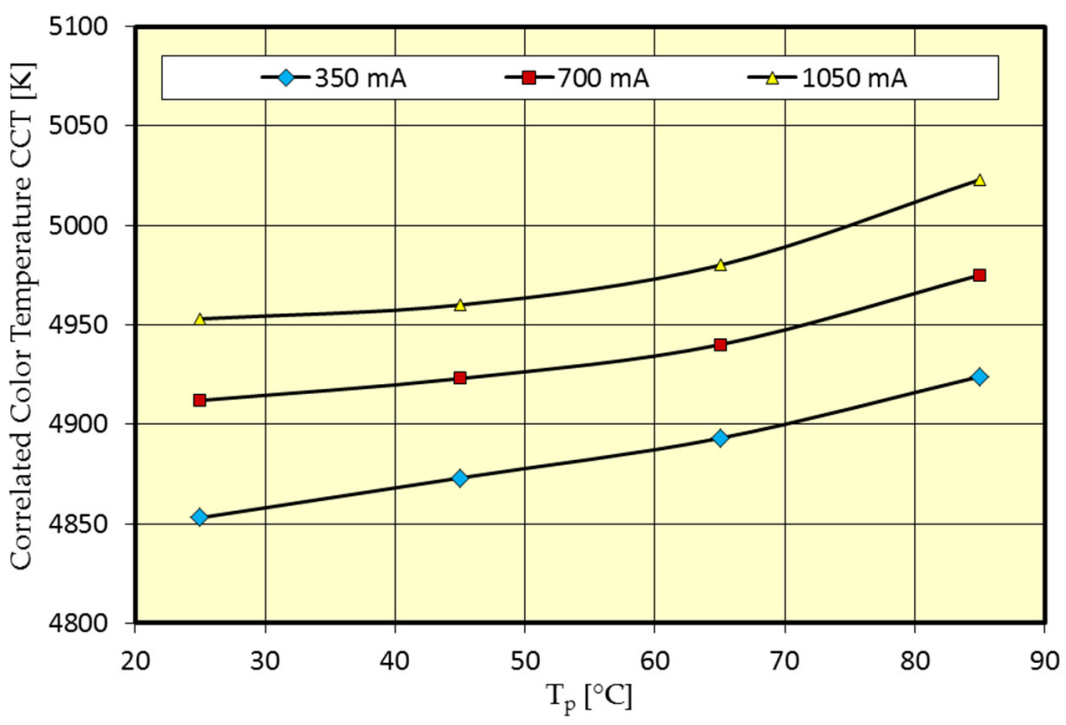

(b)

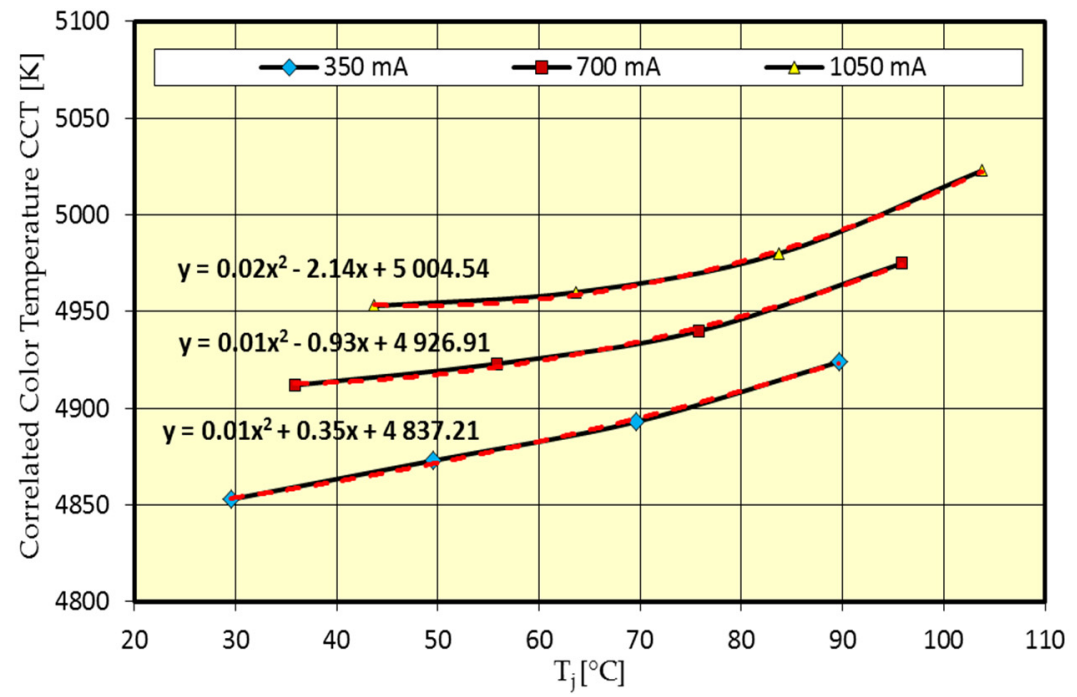

(c)

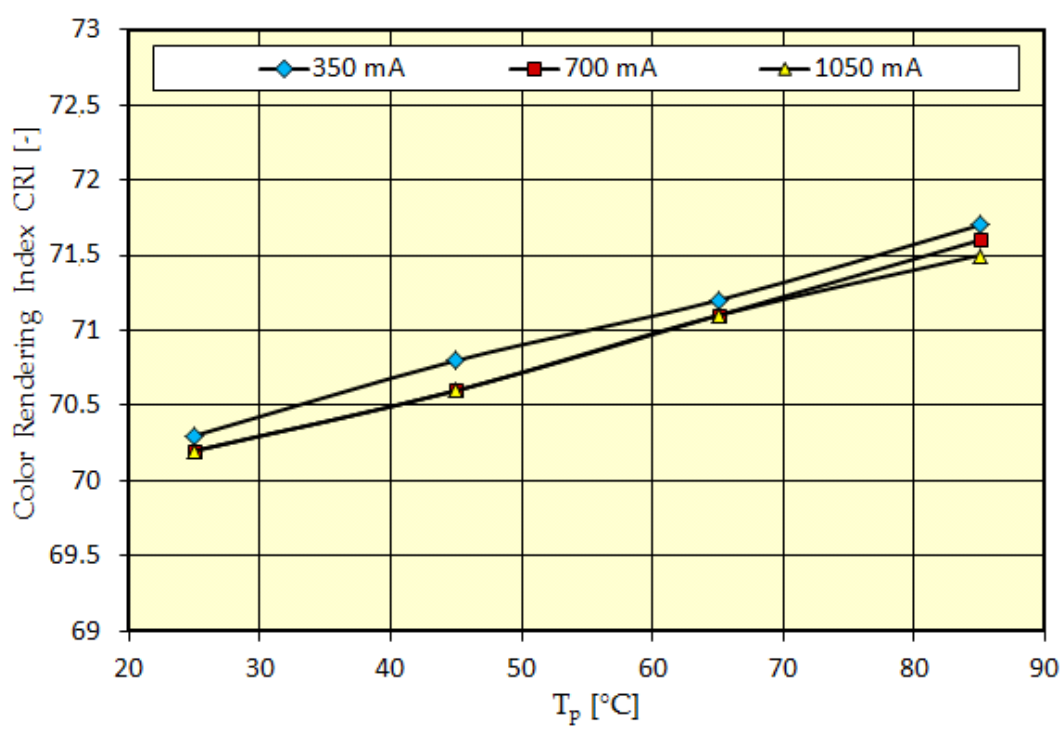

Figure 3. Cont. 


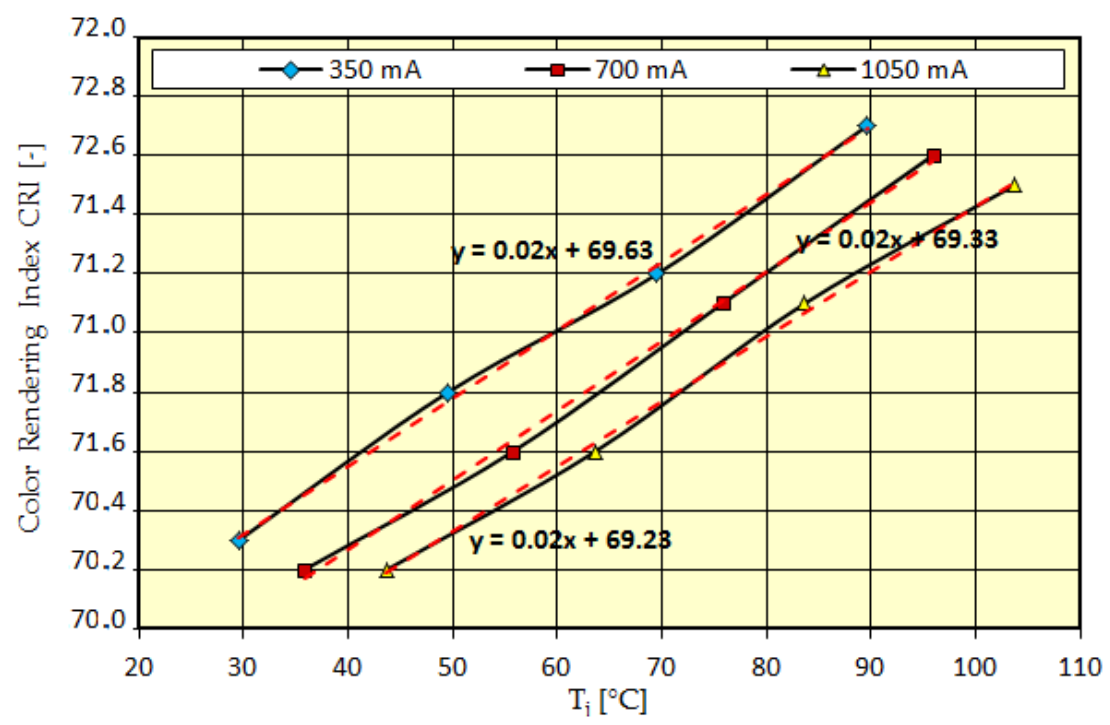

Figure 3. The effect of $T_{p}$ and $T_{j}$ temperature on lighting parameters for the studied LED source: (a) luminous flux $\Phi$; (b) CCT and (c) CRI.

To model the LED panel lighting parameters, it is necessary to perform simulation tests on the impact of panel source temperature on lighting parameters. One of the main factors affecting the accuracy of the simulation is correctly determined optical efficiency and directly related to it thermal power of LED sources. Optical efficiency, often called extraction efficiency, is a key factor in influencing LED luminous efficiency. Photons generated in the $p-n$ junction could not escape into free space completely. Extraction efficiency is lower, which is associated with several loss mechanisms such as absorption by the metal electrode, reabsorption in the substrate and and absorption by the bulk material, because of the total internal reflection. Various design solutions for LED sources are currently being developed to increase the efficiency of generating photons in the active region. The main methods that have been tried are as follows: resonant cavity, geometrically shaped chips, distributed Bragg reflector (DBR), patterned substrate and photonic crystal, surface roughening, and so on $[45,46]$.

The extraction efficiency is defined as [45,46]:

$$
\eta_{\text {extraction }}=\frac{\text { number of photons emitted into free space per second }}{\text { number of photons emitted from active region per second }}
$$

Finally, the optical efficiency $\eta_{0}$, also known as radiant efficiency, is defined as:

$$
\eta_{o}=\frac{P_{o}}{I_{F} \cdot V_{F}}=\frac{P_{o}}{P_{e}}
$$

where: $P_{o}$-optical power emitted into free space from an LED and $P_{e}$-electrical power supplied to the LED.

Photons that are not emitted into the free space are lost as heat. Heat power can be determined on the basis of the equation:

$$
P_{H}=\left(1-\eta_{0}\right) \cdot P_{e}
$$

Based on the above equations, the optical efficiency $\eta_{o}$ and heat power $P_{H}$ of the tested LED source were determined. The results are presented in Table 1. The main factor affecting the optical efficiency $\eta_{o}$ was the value of the forward current $I_{F}$. The highest efficiency $\eta_{o}$ of approx. $48 \%$ was obtained for $I_{F}=350 \mathrm{~mA}$, while for $I_{F}=1050 \mathrm{~mA}$, the efficiency $\eta_{0}$ was $38 \%$. The increase of the temperature by $60{ }^{\circ} \mathrm{C}$ resulted in the reduction of $\eta_{0}$ efficiency by approx. $2 \%$.

The effect of temperature on the spectral distribution of the tested LED source is shown in Figure 4. An increase in the temperature value caused a decrease in the spectral distribution amplitude at a 
given value of the $I_{F}$ current. With the increasing temperature $T_{p}$, there was also a noticeable shift in the dominant wavelength towards the longer wavelength.

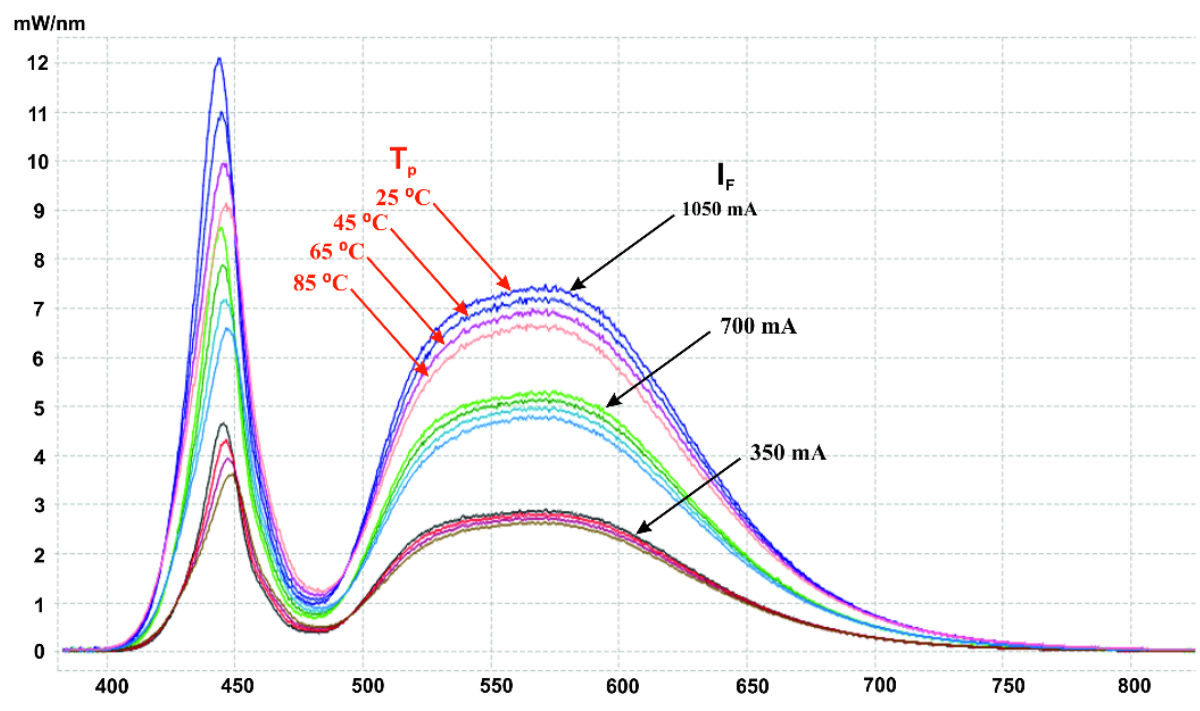

Figure 4. The effect of temperature and forward current on spectral distribution for the studied LED source.

\subsection{Thermal Modeling of the LED Panel}

An example of an analytical model of a multi-source LED panel is shown in Figure 5.

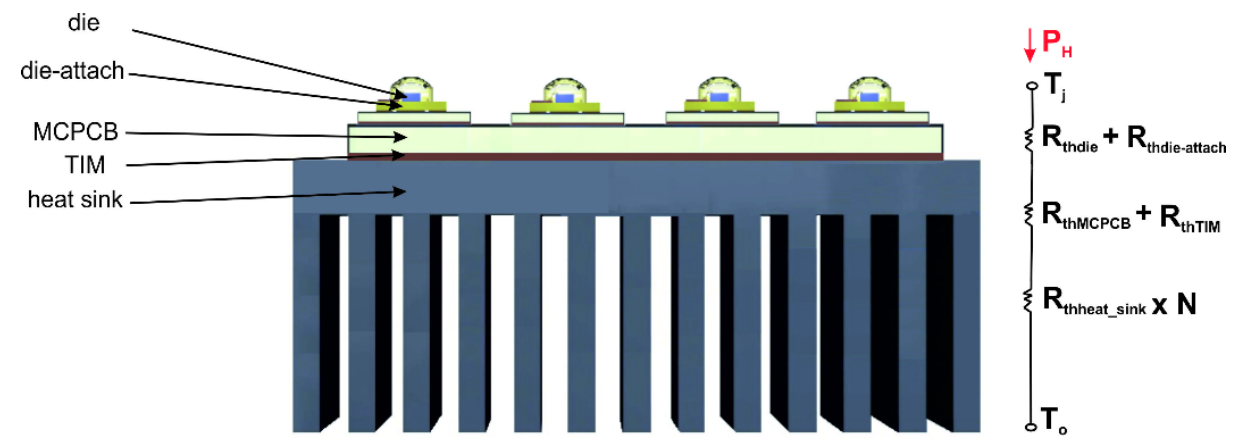

Figure 5. The components of a thermal circuit with many semiconductor light sources.

On the common surface of the MCPCB printed circuit and the common heat sink, N LEDs are installed, with the same heat output of each source equal to $P_{H}$. The total thermal resistance of the LED panel can be determined as the sum of individual thermal resistances [47]:

$$
R t h_{\text {total }}=R t h_{\text {die }}+R t h_{\text {die-attach }}+R t h_{M C P C B}+R t h_{T I M}+N \cdot R t h_{\text {heat_sink }}
$$

The thermal resistance $R t h_{\text {die }}$ and $R t h_{\text {die-attach }}$ can be determined in a simplified manner, where one-dimensional thermal resistance is assumed for conduction in a flat wall. The equation takes the form [47]:

$$
R t h=\frac{g}{k \cdot A}
$$

where: $g$-thickness, $k$-thermal conductivity, $A$-surface of the layer.

The MCPCB printed circuit is usually made of three material layers (aluminum, dielectric and copper). The thermal resistance $R t h_{M C P C B}$ is determined for all layers together, taking into account the phenomenon of heat dissipation. In addition, the thermal resistance of $R t h_{T I M}$ thermally conductive material should be considered together with a printed circuit, forming a four-layer structure. 
The Palisoc equation for a four-layer system can be used to determine the thermal resistance in a multilayer system. However, this solution is very complex, requiring a large number of calculations. In addition, the problem is analyzed for an infinite plate, and the solution does not take into account the effect of the finite size of the substrate [48].

A Masana analytical solution can also be used in this case, which is not limited by the number of layers. However, it is associated with simplifications regarding the omission of the heat transfer coefficient $h$, and thermal couplings between the inner layers [49].

Determining the heat resistance of the heat sink $N \cdot R t h_{\text {heat_sink }}$ is a significant difficulty, where the thermal resistance associated with the arrangement of LED sources should be taken into account. Muzychka's solution is used to determine it (Figure 6):

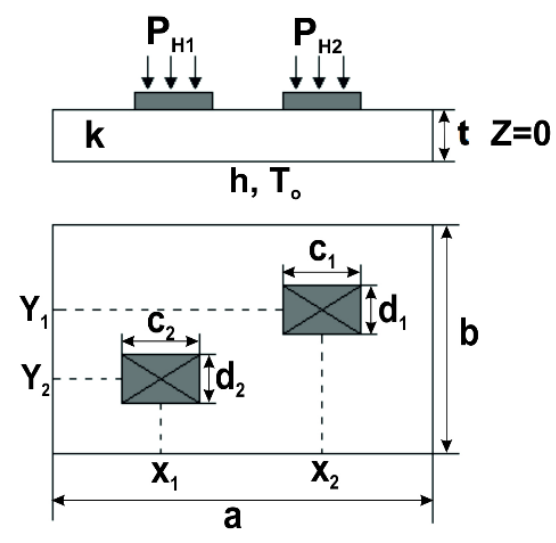

Figure 6. Diagram of Muzychka solution for a plate with two heat sources.

The temperature distribution on the surface of the heat sink is obtained using the superposition method. For $N$ installed heat sources, the surface temperature distribution is represented by [50]:

$$
\begin{gathered}
T(x, y, 0)-T_{o}=\sum_{i=1}^{N} \theta_{i}(x, y, 0) \\
\theta_{i}(x, y, 0)=A_{0}^{i}+\sum_{m=1}^{\infty} A_{m}^{i} \cos (\lambda x)+\sum_{n=1}^{\infty} A_{n}^{i} \cos (\delta y) \\
+\sum_{m=1}^{\infty} \sum_{n=1}^{\infty} A_{m n}^{i} \sum_{m=1}^{\infty} A_{m}^{i} \cos (\lambda x) \cos (\delta y) \\
A_{m}^{i}=\frac{2 P_{H i}\left[\sin \left(\frac{\left(2 x_{i}+c_{i}\right)}{2} \lambda_{m}\right)-\sin \left(\frac{\left(2 x_{i}-c_{i}\right)}{2} \lambda_{m}\right)\right]}{a b c_{i} k \lambda_{m}^{2} \varphi\left(\lambda_{m}\right)} \\
A_{n}^{i}=\frac{2 P_{H i}\left[\sin \left(\frac{\left(2 y_{i}+d_{i}\right)}{2} \delta_{n}\right)-\sin \left(\frac{\left(2 y_{i}-d_{i}\right)}{2} \delta_{n}\right)\right]}{a b d_{i} k \delta_{m}^{2} \varphi\left(\delta_{n}\right)} \\
A_{m n}^{i}=\frac{16 Q_{i} \cos \left(\lambda_{m} x_{i}\right) \sin \left(\frac{1}{2} \lambda_{n} c_{i}\right) \cos \left(\delta_{n} y_{i}\right) \sin \left(\frac{1}{2} \delta_{n} d_{i}\right)}{a b c_{i} d_{i} k \beta_{m n} \lambda_{m} \delta_{n} \varphi\left(\beta_{m n}\right)}
\end{gathered}
$$

where: $\lambda=\frac{m \pi}{a}, \delta=\frac{n \pi}{b}, \beta=\sqrt{\lambda^{2}+\delta^{2}}, \varphi(\omega)=\frac{\omega \sinh (\omega t)+\frac{h}{k} \cosh (\omega t)}{\omega \cosh (\omega t)+\frac{h}{k} \sinh (\omega t)}$ and $\omega$ is replaced by $\lambda, \delta$ and $\beta$, respectively.

The analytical solutions presented are a generalized description of thermal processes and can only be used for the non-complex temperature analysis of LED sources. The above solutions contain significant simplifications, limiting the possibility of their use in complex structures, including the ability to define the simple geometry of the radiation system or heat sources (usually a rectangle or circle). 
For a detailed temperature analysis of LED panels with a complex structure, software based on FEM (finite element method) or CFD (computational fluid mechanics) can be used. The above software enables the analysis of complex geometric constructions, taking into account all types of heat transfer, as well as a three-dimensional analysis of the temperature distribution.

In the next stage of research related to the modeling of LED panel lighting parameters, thermal simulation tests were carried out to determine the junction temperature of individual LED sources, which affects the lighting parameters, as presented in Section 2.1.

For detailed thermal tests, a panel with 12 LED sources was used. Its parameters were determined in Table 1. The sources were installed on MCPCB in two rows, each of which consisted of 6 sources. The size of the MCPCB printed circuit board was $146 \times 44 \mathrm{~mm}$. The heat sink of LED panel was made of an Al5052 aluminum alloy. Its base had dimensions of $183 \times 80 \mathrm{~mm}$ with a thickness $H_{B H}=4 \mathrm{~mm}$. On the upper surface of the base, 13 fins of the height $H_{f}=29 \mathrm{~mm}$ were formed. In addition, all fins, except the outer ones, have deformations in the form of cylinders (Figure 7). The geometry and shape of the heat sink were developed based on conducted and published research in this journal [23].
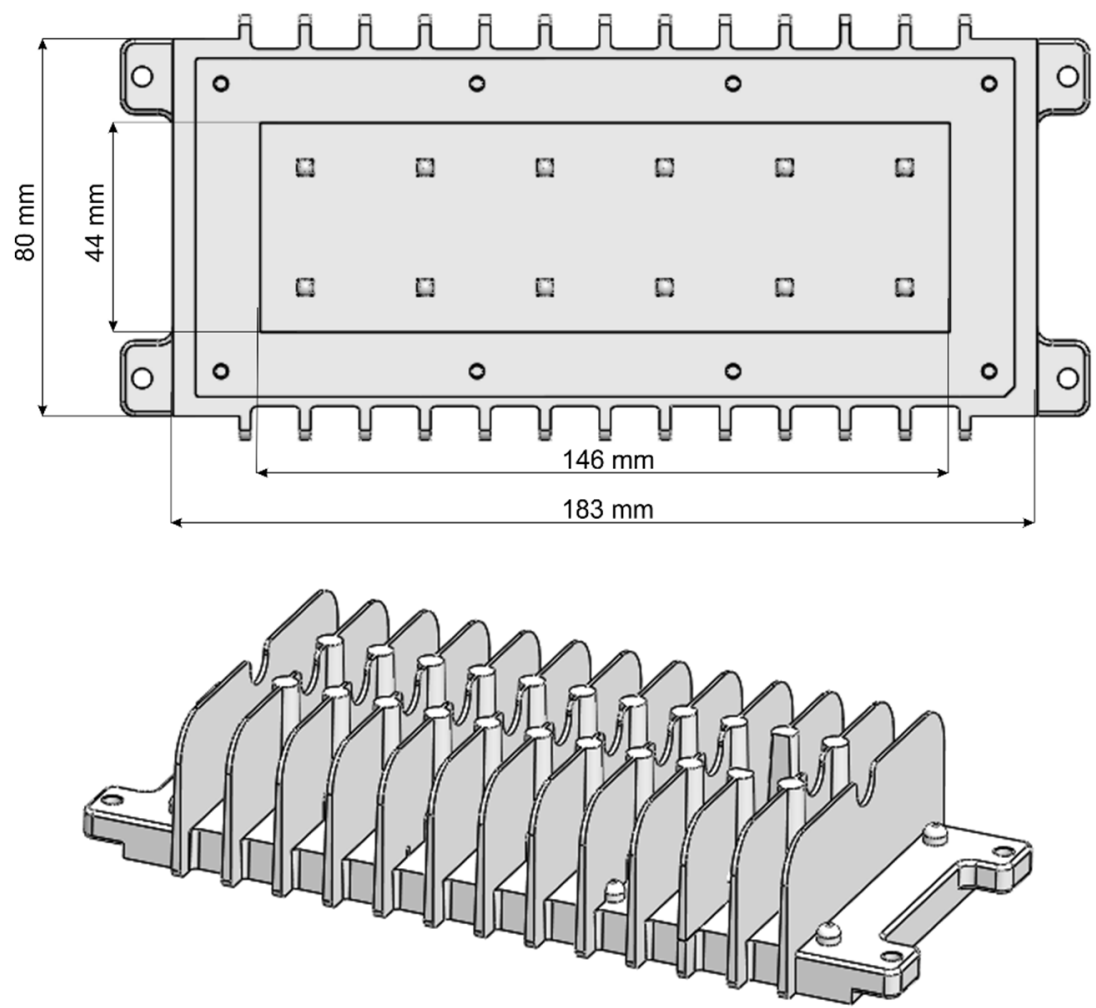

Figure 7. Computer model of the tested LED panel.

The tests were implemented in Mentor Graphics FloEFD 16.2 software [51]. The selected tool has, among others, an embedded CAD module creating the analyzed 3D geometry, as well as a flow simulation module based on computational fluid mechanics, which performs advanced thermal calculations for all types of heat transport, i.e., conduction, convection, and radiation [52,53].

The parameters of the materials used in the simulation model and their physical characteristics are presented in Table 2. 
Table 2. Materials used, and their parameters for constructing the LED panel [54].

\begin{tabular}{|c|c|c|c|c|}
\hline Layer & Material & Thickness (mm) & $\begin{array}{c}\text { Thermal Conductivity } \\
k(\mathrm{~W} / \mathrm{m} \cdot \mathrm{K})\end{array}$ & $\begin{array}{c}\text { Thermal Resistance } \\
\text { Rthj-c }\left({ }^{\circ} \mathrm{C} / \mathrm{W}\right)\end{array}$ \\
\hline Heat sink & Aluminum 5052 & 4 & 140 & - \\
\hline TIM & Thermal paste & 0.1 & 3 & - \\
\hline МСРСВ & $\begin{array}{l}\text { Aluminum } 5052 \\
\text { Dielectric } \\
\text { Copper }\end{array}$ & $\begin{array}{c}1.5 \\
0.1 \\
0.035\end{array}$ & $\begin{array}{c}140 \\
2 \\
400\end{array}$ & - \\
\hline Soldering & 96.5Sn3.5Ag & 0.1 & 33 & \\
\hline LED source & - & - & - & $\begin{array}{l}8.6_{I F}=350 \mathrm{~mA} \\
8.6_{I F}=700 \mathrm{~mA} \\
8.8_{I F}=1050 \mathrm{~mA}\end{array}$ \\
\hline Lens & Epoxy resin & - & 0.2 & - \\
\hline
\end{tabular}

Simulation tests were performed for three values of forward current $I_{F}: 350,700$ and $1050 \mathrm{~mA}$. The thermal power of $P_{H}$ sources was assumed according to the results of the tests (Table 1). To determine the junction temperature $T_{j}$, the real value of the thermal resistance $R t h_{j-c}[55,56]$, described in detail and determined in [23,57], was used.

The size of the computational domain was selected based on the heat transfer characteristics and computation time. The domain length and width were set $2 L_{p}$ and $2 W_{p}$, and the height of the domain was set as $7 H_{p}$, where $L_{p}, W_{p}$ and $H_{p}$ denote the length, width and height of the LED panel, respectively. Natural convection was used as the boundary conditions for simulation. The ambient temperature $\mathrm{T} a$ was $24^{\circ} \mathrm{C}$ and the air pressure surrounding the panel $p=101.325 \mathrm{kPa}$. The simulation calculations were conducted with regard to thermal radiation and the emissivity factor $\varepsilon$ for the aluminum plate was 0.2. To define the calculation grid, we used an advanced module for adaptive meshing, which is built into the software FloEFD 16.2 software. Figure 8 shows the computational domain, while Figure 9 shows the temperature distribution of the LED panel at $I_{F}=700 \mathrm{~mA}$.

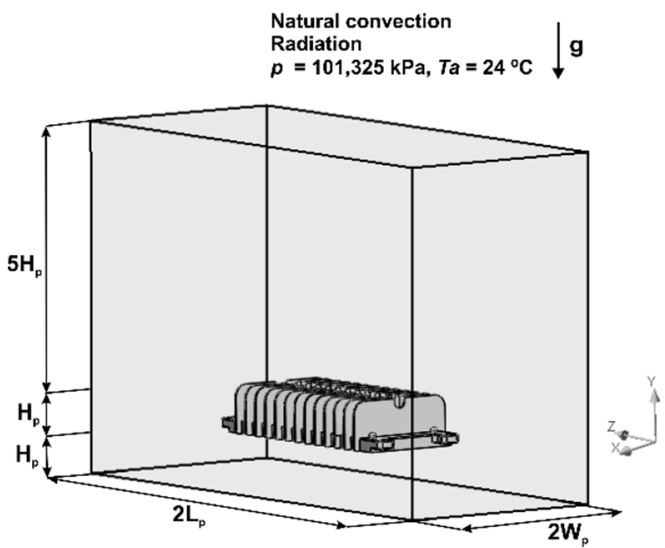

(a)

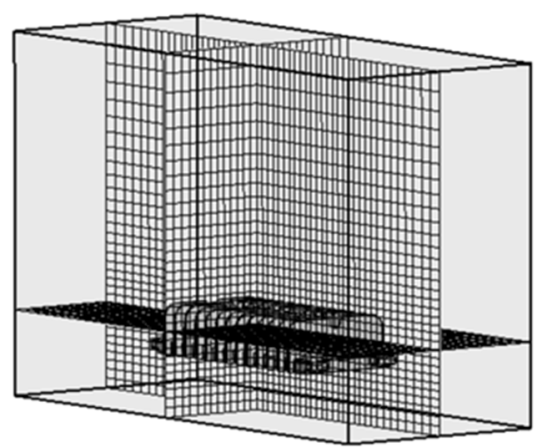

(b)

Figure 8. Simulation model of the LED panel: (a) computation domain with the assumed boundary conditions and (b) cross-section of the computation grid along the XYZ axis. 
(a)

(b)
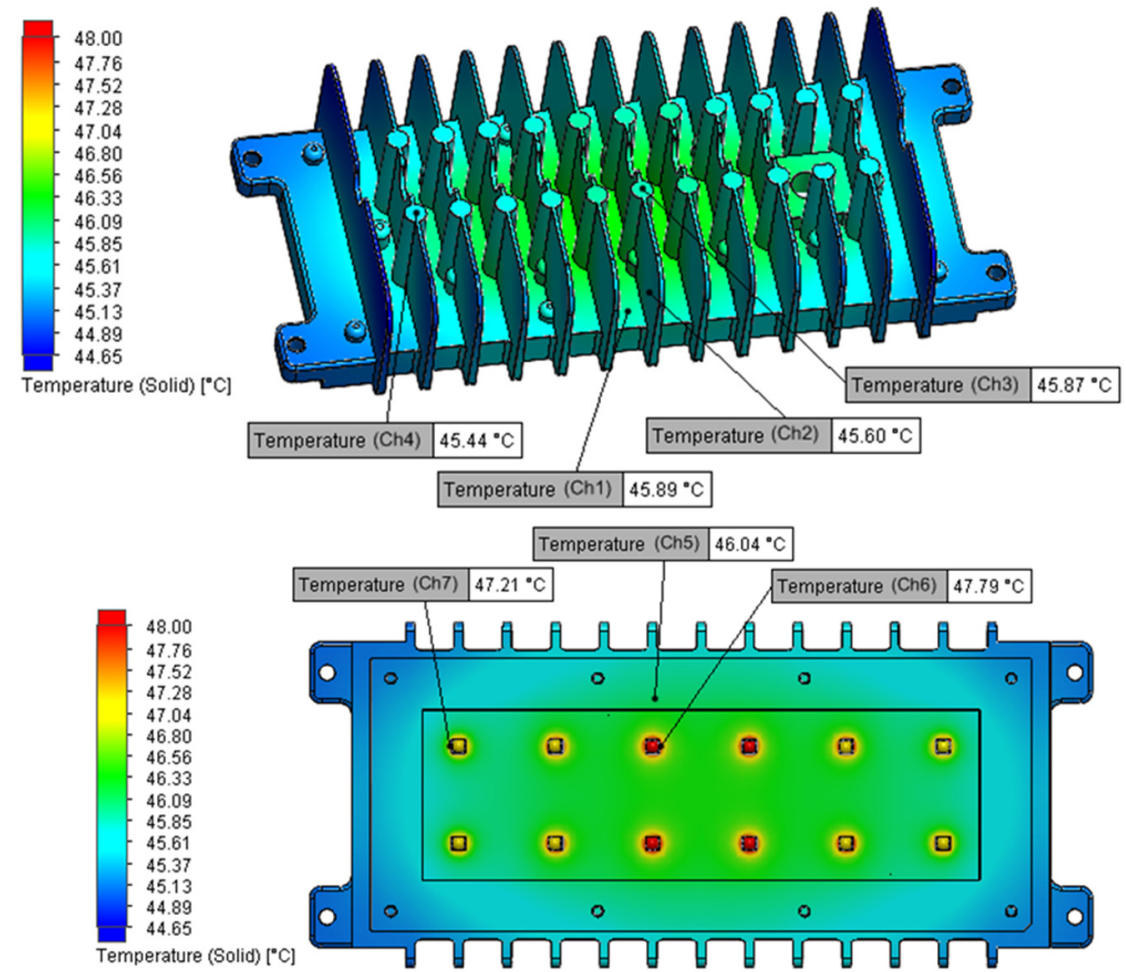

Figure 9. Temperature distribution of the LED panel for $I_{F}=700 \mathrm{~mA}$, with characteristic measuring points: (a) top view of the LED panel, (b) bottom view of the LED panel.

A very even temperature distribution on the heat sink surface was obtained. The temperature difference between the extreme and central fin of the heat sink did not exceed $1{ }^{\circ} \mathrm{C}$. The difference between the temperature of the junction LED panel source and the temperature on the fins of the heat sink (Figure 9) is small and is about $13{ }^{\circ} \mathrm{C}$, which proves effective heat dissipation.

The results of the temperature distribution of the LED panel were verified by measurements conducted on the prototype of the panel. The real measurement was made using a L200-TC Labfacility 8-channel laboratory temperature monitor [58]. Seven measuring channels were installed on the heat sink and $\mathrm{MCPCB}$, with a temperature sensor in the form of a K-type thermocouple. The LED panel measuring points were located as follows: on the upper base in the central part of the heat sink (1), on the central fin of the heat sink (2), on the fin protrusion above the central LED source (3), on the fin protrusion above the outer LED source (4), on the lower base of heat sink (5), on MCPCB at a distance of $1 \mathrm{~mm}$ from the central LED source (6) and on MCPCB at a distance of $1 \mathrm{~mm}$ from the outer LED source (7) (Figure 9).

Temperature measurements at the designated measuring points were carried out for three values of forward current $I_{F}: 350 ; 700$ and $1050 \mathrm{~mA}$. During the measurements, the LED panel was suspended in a horizontal position, and heat exchange with the ambient environment took place by free convection. The ambient temperature during the measurements was the same as the simulation temperature and was $\mathrm{T} a=24{ }^{\circ} \mathrm{C}$. Temperature values were automatically saved every $10 \mathrm{~s}$. The measurement time was one hour, so that the temperature for all measuring channels could reach the steady value. Figure 10 shows the view of the LED panel prototype and the temperature curves of the measuring channels, for forward current $I_{F}=700 \mathrm{~mA}$. 

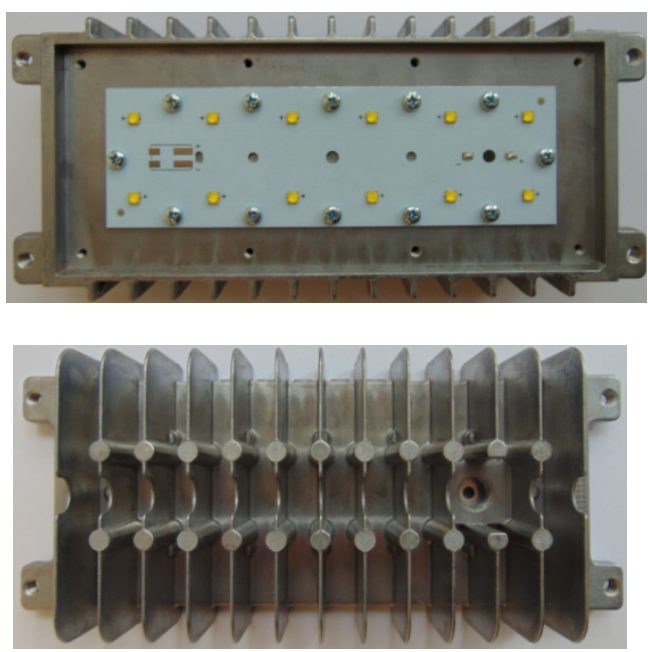

(a)

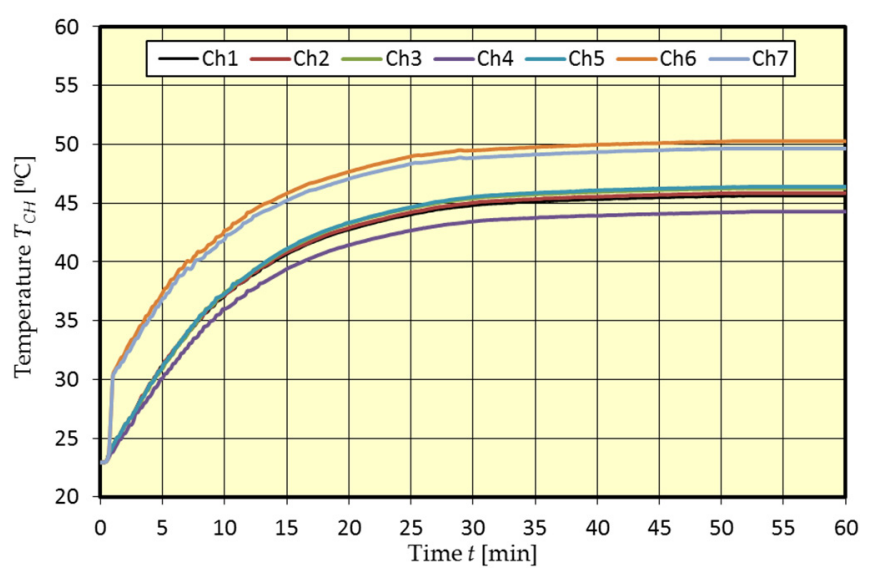

(b)

Figure 10. View of the LED panel prototype (a) and temperature curves of seven measuring channels for forward current $I_{F}=700 \mathrm{~mA}(\mathbf{b})$.

The fastest temperature increase was observed in the first ten minutes. After a time of approx. $45 \mathrm{~min}$., the temperature reached a steady state. Even temperature distribution was recorded on the heat sink surface. The temperature values recorded at the measuring points did not show large differences, only at measuring point No. 4, located on the outer fin of the heat sink, was the temperature slightly lower. The highest temperature value was obtained for measuring points No. 6 and No. 7 located on the MCPCB, in close proximity to semiconductor light sources.

The results of simulations and real measurements of temperature for all three values of $I_{F}$ forward current are presented in Table 3. The real results refer to temperature measurement after $60 \mathrm{~min}$ when the LED panel has reached a steady state. The error of simulation results was determined as represented below:

$$
\text { Error }=\frac{\mid \text { Simulation result }- \text { Real measurement } \mid}{\text { Real measurement }} \cdot 100[\%]
$$

Table 3. Comparison of temperature simulation results and real measurements in seven measuring points.

\begin{tabular}{ccccccccc}
\hline$I_{\boldsymbol{F}}[\mathrm{mA}]$ & Ch1 & Ch2 & Ch3 & Ch4 & Ch5 & Ch6 & Ch7 \\
\hline \multirow{3}{*}{350} & Simulation result $\left[{ }^{\circ} \mathrm{C}\right]$ & 34.99 & 34.86 & 35.02 & 34.87 & 35.09 & 35.90 & 35.61 \\
& Real measurement $\left[{ }^{\circ} \mathrm{C}\right]$ & 35.53 & 35.66 & 35.75 & 34.76 & 35.74 & 37.46 & 37.3 \\
& Error [\%] & 1.52 & 2.25 & 2.05 & 0.32 & 1.82 & 4.17 & 4.54 \\
\hline \multirow{3}{*}{700} & Simulation result $\left[{ }^{\circ} \mathrm{C}\right]$ & 45.89 & 45.60 & 45.87 & 45.44 & 46.04 & 47.79 & 47.21 \\
& Real measurement $\left[{ }^{\circ} \mathrm{C}\right]$ & 45.62 & 45.86 & 46.25 & 44.27 & 46.4 & 50.26 & 49.65 \\
& Error [\%] & 0.60 & 0.57 & 0.83 & 2.65 & 0.78 & 4.92 & 4.92 \\
\hline \multirow{2}{*}{1050} & Simulation result $\left[{ }^{\circ} \mathrm{C}\right]$ & 55.98 & 55.49 & 56.14 & 55.40 & 56.45 & 60.2 & 59.1 \\
& Real measurement $\left[{ }^{\circ} \mathrm{C}\right]$ & 55.31 & 56.04 & 56.43 & 53.46 & 57.02 & 63.14 & 62.2 \\
& Error [\%] & 1.22 & 0.99 & 0.52 & 3.63 & 1.00 & 4.66 & 4.92 \\
\hline
\end{tabular}

A high compliance of simulations and real results was obtained. The largest error was recorded at the sixth and seventh measuring point, located directly at the semiconductor light sources. Its value did not exceed $5 \%$ for all three tested values of forward current $I_{F}$. A bigger difference between simulation and real results obtained for the measuring points can be attributed to a relatively larger temperature gradient in close proximity of LED sources. 
The presented thermal model of the LED panel and high compliance of the simulation and real results is the basis for modeling the panel's luminous parameters, which depend on the temperature of individual sources.

\subsection{Modeling of LED Panel Luminous Parameters}

The influence of temperature on the lighting parameters of a single LED source and a reliable thermal analysis of the panel presented in the preceding part of the paper provide the basis for determining the lighting parameters of the LED panel.

For the LED panel studied, the junction temperature $T_{j}$ of individual sources was simulated for three values of forward current $I_{F}: 350,700$ and $1050 \mathrm{~mA}$. An example of the panel temperature distribution and the junction temperature $T_{j}$ for $I_{F}=700 \mathrm{~mA}$ is shown in Figure 11 .

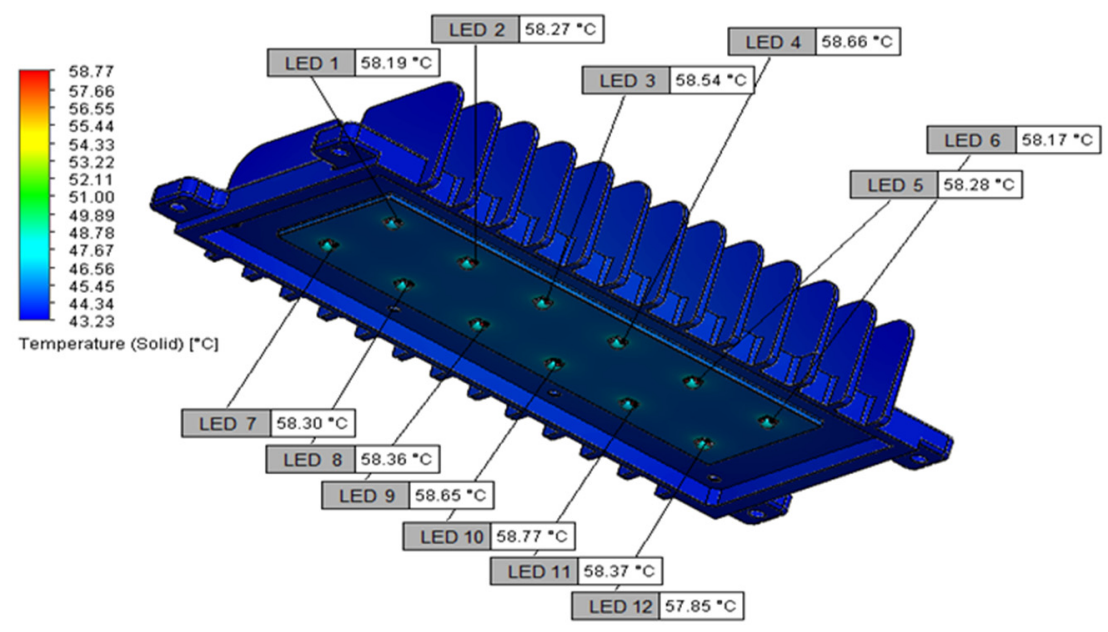

Figure 11. The distribution of panel temperature and junction temperature $T_{j}$ of panel sources for $I_{F}=700 \mathrm{~mA}$.

Luminous flux $\Phi$, color temperature CCT and color rendering index CRI of individual LED panel sources were determined, based on the simulation of the source junction temperature and the approximation equations specified in Section 2.1 (Figure 3).

As an example, the following is the calculation for the $L E D 1$ source for $I_{F}=700 \mathrm{~mA}$ :

- luminous flux $\Phi$

$$
\Phi_{L E D 1}=-0.54 \cdot T_{j}+337.20=-0.54 \cdot 58.19+337.20=305.78 \mathrm{~lm}
$$

- correlated colour temperature CCT

$$
C C T_{L E D 1}=0.01 \cdot T_{j}^{2}-0.93 \cdot T_{j}+4926.91=0.01 \cdot 58.19^{2}-0.93 \cdot 58.19+4926.91=4906.65 \mathrm{~K}
$$

- colour rendering index $C R I$

$$
C R I_{L E D 1}=0.02 \cdot T_{j}+69.33=0.02 \cdot 58.19+69.33=70.49
$$

The output lighting parameters of the LED panel were determined based on:

$$
\begin{gathered}
\Phi_{\text {panel_LED }}=\Phi_{L E D 1}+\Phi_{L E D 2}+\ldots+\Phi_{L E D 12} \\
C C T_{\text {panel_LED }}=\frac{C C T_{L E D 1}+C C T_{L E D 2}+\ldots+C C T_{L E D 12}}{\text { number of } L E D \text { panel sources }}
\end{gathered}
$$




$$
C R I_{\text {panel_LED }}=\frac{C R I_{L E D 1}+C R I_{L E D 2}+\ldots+C R I_{L E D 12}}{\text { number of } L E D \text { panel sources }}
$$

where: $\Phi_{\text {panel_LED }}$-luminous flux of panel LED, $\Phi_{L E D}$-luminous flux of LED source, $C C T_{\text {panel_LED }}$-correlated color temperature of panel LED, $C C T_{L E D}$-correlated color temperature of LED source, $C R I_{\text {panel_LED }}$-color rendering index of panel LED, $C R I_{L E D}$-color rendering index of LED source.

Table 4 presents the calculated lighting parameters of the analyzed LED panel for all three values of $I_{F}$ forward current.

Table 4. Calculated lighting parameters for individual sources and the LED panel.

\begin{tabular}{|c|c|c|c|c|c|c|c|c|}
\hline & \multicolumn{4}{|c|}{$I_{F}=350 \mathrm{~mA}$} & \multicolumn{4}{|c|}{$I_{F}=700 \mathrm{~mA}$} \\
\hline & $T_{j}\left[{ }^{\circ} \mathrm{C}\right]$ & $\Phi[1 \mathrm{~m}]$ & $\mathrm{CCT}[\mathrm{K}]$ & CRI [-] & $T_{j}\left[{ }^{\circ} \mathrm{C}\right]$ & $\Phi[\mathrm{lm}]$ & $\mathrm{CCT}[\mathrm{K}]$ & CRI [-] \\
\hline LED 1 & 40.66 & 169.69 & 4867.97 & 70.44 & 58.19 & 305.78 & 4906.65 & 70.49 \\
\hline LED 2 & 40.73 & 169.67 & 4868.05 & 70.44 & 58.27 & 305.73 & 4906.67 & 70.50 \\
\hline LED 3 & 40.84 & 169.64 & 4868.18 & 70.45 & 58.54 & 305.59 & 4906.74 & 70.50 \\
\hline LED 4 & 40.89 & 169.63 & 4868.24 & 70.45 & 58.66 & 305.52 & 4906.77 & 70.50 \\
\hline LED 5 & 40.73 & 169.67 & 4868.05 & 70.44 & 58.28 & 305.73 & 4906.68 & 70.50 \\
\hline LED 6 & 40.65 & 169.69 & 4867.96 & 70.44 & 58.17 & 305.79 & 4906.65 & 70.49 \\
\hline LED 7 & 40.71 & 169.68 & 4868.03 & 70.44 & 58.30 & 305.72 & 4906.68 & 70.50 \\
\hline LED 8 & 40.77 & 169.66 & 4868.10 & 70.45 & 58.36 & 305.69 & 4906.69 & 70.50 \\
\hline LED 9 & 40.89 & 169.63 & 4868.24 & 70.45 & 58.65 & 305.53 & 4906.76 & 70.50 \\
\hline LED 10 & 40.94 & 169.62 & 4868.30 & 70.45 & 58.77 & 305.46 & 4906.79 & 70.51 \\
\hline LED 11 & 40.77 & 169.66 & 4868.10 & 70.45 & 58.37 & 305.68 & 4906.70 & 70.50 \\
\hline LED 12 & 40.5 & 169.73 & 4867.79 & 70.44 & 57.85 & 305.96 & 4906.58 & 70.49 \\
\hline \multirow[t]{3}{*}{ LED panel } & - & 2035.96 & 4868.09 & 70.45 & & 3668.18 & 4906.70 & 70.50 \\
\hline & \multicolumn{4}{|c|}{$I_{F}=1050 \mathrm{~mA}$} & & & & \\
\hline & $T_{j}\left[{ }^{\circ} \mathrm{C}\right]$ & $\Phi[1 \mathrm{~m}]$ & $\mathrm{CCT}[\mathrm{K}]$ & CRI [-] & & & & \\
\hline LED 1 & 78.76 & 417.45 & 4960.06 & 70.81 & & & & \\
\hline LED 2 & 78.82 & 417.40 & 4960.12 & 70.81 & & & & \\
\hline LED 3 & 79.18 & 417.10 & 4960.48 & 70.81 & & & & \\
\hline LED 4 & 79.42 & 416.91 & 4960.73 & 70.82 & & & & \\
\hline LED 5 & 78.86 & 417.36 & 4960.16 & 70.81 & & & & \\
\hline LED 6 & 78.71 & 417.49 & 4960.01 & 70.80 & & & & \\
\hline LED 7 & 78.98 & 417.27 & 4960.28 & 70.81 & & & & \\
\hline LED 8 & 79.03 & 417.23 & 4960.33 & 70.81 & & & & \\
\hline LED 9 & 79.73 & 416.65 & 4961.06 & 70.82 & & & & \\
\hline LED 10 & 79.64 & 416.73 & 4960.96 & 70.82 & & & & \\
\hline LED 11 & 79.07 & 417.19 & 4960.37 & 70.81 & & & & \\
\hline LED 12 & 78.15 & 417.95 & 4959.45 & 70.79 & & & & \\
\hline LED panel & - & 5006.71 & 4960.33 & 70.81 & & & & \\
\hline
\end{tabular}

For all three considered values of the forward current, the uniform temperature distribution and the approximate value of the junction temperature affecting the lighting parameters of the LED panel were obtained. For $350 \mathrm{~mA}$, the temperature was about $41^{\circ} \mathrm{C}$, for $700 \mathrm{~mA}$ about $58^{\circ} \mathrm{C}$, and for $1050 \mathrm{~mA}$ about $79^{\circ} \mathrm{C}$. An even temperature distribution proves the correct heat sink design and effective heat dissipation. A similar junction temperature of all panel sources influenced similar values of lighting parameters of individual light sources. In this case, it is possible to estimate the output light parameters of the panel based on the information contained in the data sheet of light sources. Manufacturers usually only declare the effect of forward current and junction temperature on the luminous flux, however, there is no information regarding the color temperature and color rendering index. For panels containing a larger number of light sources, the temperature difference between the extreme and central light sources may be much larger, also resulting in an uneven distribution of light 
parameters. The uneven temperature distribution of LED sources can also be affected by incorrect design of the cooling system. In this case, determining the output light parameters based on catalog data may be subject to a significant error. The determination of the correct lighting parameters with an acceptable error should be supported by a complex thermal analysis using, e.g., CFD software.

To verify the simulation values of lighting parameters, real measurements were carried out on the prototype (Figure 10). The tests were conducted on a measuring stand, which included an integrating sphere with a diameter of $2 \mathrm{~m}$ (Figure 12a) and a Konica Minolta CS-2000 spectroradiometer [59] (Figure 12b). The relative uncertainty of measurement did not exceed $4 \%$. Measurements of lighting parameters were made after $60 \mathrm{~min}$, when the LED panel reached a thermal steady state. Table 5 summarizes the results obtained in real measurements and the results obtained from simulation tests.

(a)

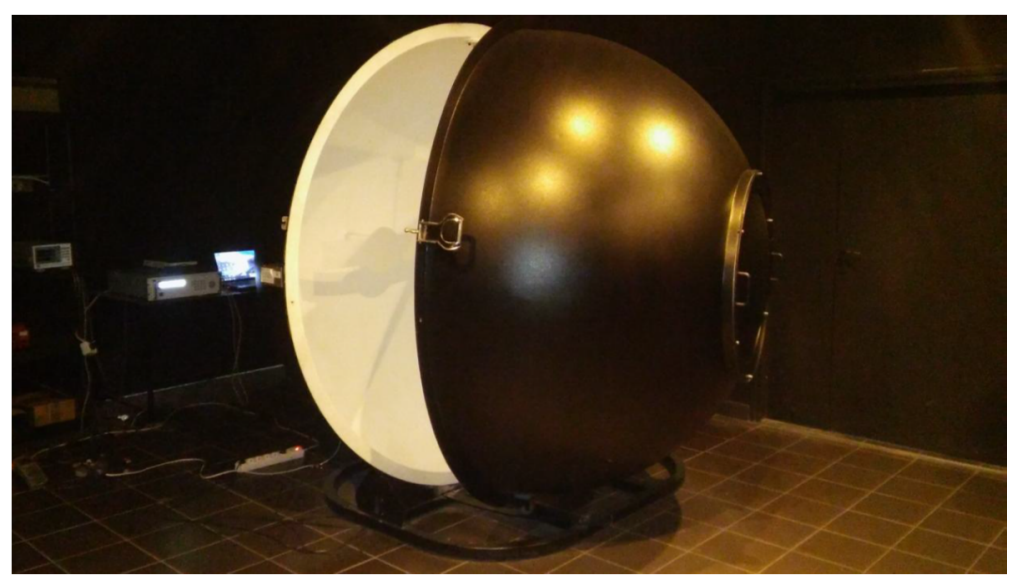

(b)

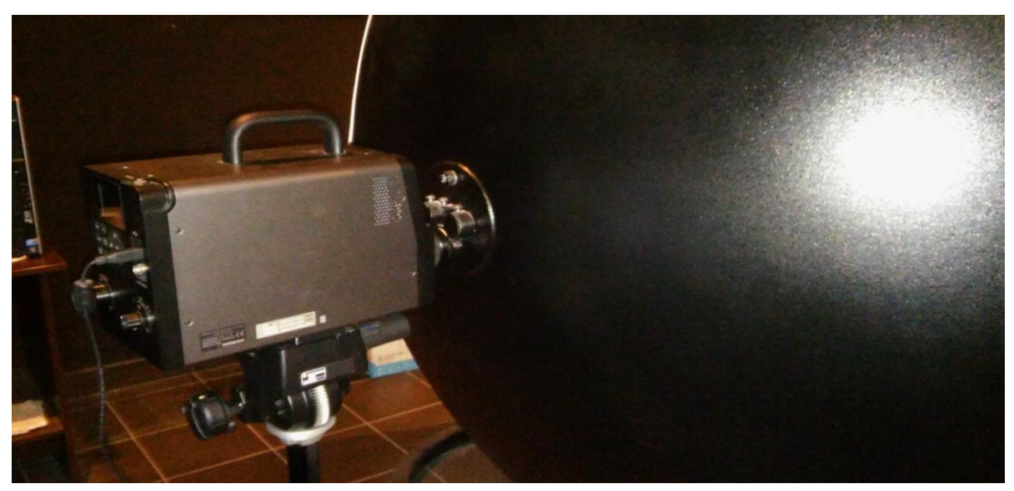

Figure 12. Laboratory stand for measuring the lighting parameters of the LED panel: (a) integrating sphere with a diameter of $2 \mathrm{~m}$; (b) CS-2000 spectroradiometer.

The obtained results (luminous flux $\Phi$, color temperature $C C T$, color rendering index $C R I$ ) show the high compliance of simulation results with experimental tests-the error value did not exceed $4.4 \%$. The smallest error was determined for $I_{F}=350 \mathrm{~mA}$, with the largest for $I_{F}=1050 \mathrm{~mA}$. 
Table 5. The results of simulations and real measurements.

\begin{tabular}{|c|c|c|c|c|}
\hline & & Luminous Flux $\Phi[1 \mathrm{~m}]$ & $\begin{array}{l}\text { Correlated Colour } \\
\text { Temperature } C C T[\mathrm{~K}]\end{array}$ & $\begin{array}{l}\text { Colour Rendering } \\
\text { Index CRI [-] }\end{array}$ \\
\hline \multirow{3}{*}{ 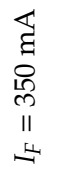 } & Simulation result $\left[{ }^{\circ} \mathrm{C}\right]$ & 2035.96 & 4868.09 & 70.45 \\
\hline & Real measurement $\left[{ }^{\circ} \mathrm{C}\right]$ & 2011.43 & 4998 & 70.24 \\
\hline & Error $[\%]$ & 1.22 & 2.60 & 0.30 \\
\hline \multirow{3}{*}{ 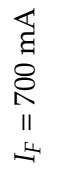 } & Simulation result $\left[{ }^{\circ} \mathrm{C}\right]$ & 3668.18 & 4906.70 & 70.50 \\
\hline & Real measurement $\left[{ }^{\circ} \mathrm{C}\right]$ & 3569.09 & 5051 & 70.29 \\
\hline & Error [\%] & 2.78 & 2.86 & 0.30 \\
\hline \multirow{3}{*}{ 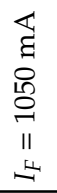 } & Simulation result $\left[{ }^{\circ} \mathrm{C}\right]$ & 5006.71 & 4960.33 & 70.81 \\
\hline & Real measurement $\left[{ }^{\circ} \mathrm{C}\right]$ & 4797.58 & 5102 & 70.46 \\
\hline & Error $[\%]$ & 4.36 & 2.78 & 0.50 \\
\hline
\end{tabular}

\section{Conclusions}

The junction temperature $T_{j}$ of semiconductor light sources significantly affects the lifetime of the sources, as well as their electrical and lighting parameters. Real tests carried out for a single LED source showed the influence of $T_{j}$ on the luminous flux $\Phi$, color temperature $C C T$ and color rendering index CRI. The increase of temperature by $60^{\circ} \mathrm{C}$ resulted in the reduction of luminous flux $\Phi$ by approx. $10 \%$, and the shift of color temperature CCT towards the cooler direction by $70 \mathrm{~K}$. The temperature increase also improved the value of color rendering index CRI by about 1.5. A high value of optical efficiency $\eta_{o}$ ranging from $37 \%$ to $50 \%$, depending on the value of forward current $I_{F}$, was obtained for the tested LED source, which proves that the optical efficiency $\eta_{0}$ of latest commercial LED light sources can be higher than $30 \%$-often reported in the literature.

It is difficult to determine the output light parameters of the LED panel, as their value depends on the junction temperature $T_{j}$ of many sources thermally coupled on a common heat sink. The influence of junction temperature and forward current on the lighting parameters of individual sources declared by manufacturers can be used to determine approximate panel values in simple systems and refer mainly to the luminous flux. In the case of complex panels with many LED sources, as well as to determine additional lighting parameters of the panel, it is necessary to carry out a complex thermal analysis using, e.g., CFD software.

The simulation results of the LED panel temperature distribution presented in the paper showed high compliance with the real results, and the error did not exceed $5 \%$. The compliance was achieved by determining the real thermal power $P_{H}$ for the tested LED source, and taking into account the real thermal resistance of the $R t h_{j-c}$ determined in the calculations. Thermal working conditions of LED panel sources are shaped by many factors, including the number of LEDs, their arrangement, the design of the printed circuit, the design of the heat sink, the thermal interface material used or the type of heat exchange with the ambient environment. The presented thermal model allows for their analysis and can be used to optimize the design of the panel or lighting fixture with LED sources. As a result, the lowest $T_{j}$ temperature can be obtained.

The presented thermal model, together with the results of the temperature distribution of the LED panel, provided the basis for determining the initial lighting parameters of the panel. The determined $T_{j}$ temperature of individual sources and the results of tests for a single LED source enabled the determination of the luminous flux $\Phi$, color temperature $C C T$ and color rendering index $C R I$ for the LED panel. The simulation results were confirmed by real tests on the prototype, and the error did not exceed $4.4 \%$. 
The results presented in the paper confirm the validity of computational tools used to design and evaluate the thermal operating conditions of semiconductor light sources. The use of correct model parameters, including, among others, heat power $P_{H}$ or thermal resistance $R t h_{j-c}$, makes it possible to obtain reliable simulation results related to shaping the distribution of both temperature and output parameters of the LED panel.

Author Contributions: The measurements of LED source parameters were made by H.W. The results of simulation studies presented in this manuscript and their assessment was carried out by K.B. Finally, A.R. and S.R. supervised the research and prepared the manuscript. All authors have read and agreed to the published version of the manuscript.

Funding: This research received no external funding.

Conflicts of Interest: The authors declare no conflict of interest.

\section{Nomenclature}

$\varepsilon \quad$ emissivity factor

$\eta_{0} \quad$ optical efficiency

$\Phi \quad$ luminous flux

CCT correlated color temperature

CRI color rendering index

$H_{B H} \quad$ heatsink base height

$H_{f} \quad$ heat sink fin height

$H_{p} \quad$ LED panel height

$I_{F} \quad$ forward current

$k \quad$ thermal conductivity

$L_{p} \quad$ LED panel length

$P_{e} \quad$ electrical power

$P_{H} \quad$ heat power

$P_{0} \quad$ optical power

$R t h_{j-c} \quad$ LED thermal resistance junction to case

$T_{a} \quad$ ambient temperature

$T_{j} \quad$ junction temperature

$T_{p} \quad$ peltier module temperature

$V_{F} \quad$ forward voltage

$W_{p} \quad$ LED panel width

\section{References}

1. Chen, H.; Tan, S.; Hui, S. Analysis and modeling of high-power phosphor-coated white light-emitting diodes with a large surface area. IEEE Trans. Power Electron. 2015, 30, 3334-3344. [CrossRef]

2. Acuna, P.C.; Leyre, J.; Audenaert, J.; Meuret, Y.; Deconinck, G.; Hanselaer, P. Impact of geometrical and optical parameters on the performance of a cylindrical remote phosphor LED. IEEE Photonics J. 2015, 7. [CrossRef]

3. Jagerbrand, A. LED (Light-Emitting Diode) road lighting in practice: An evaluation of compliance with regulations and improvements for further energy savings. Energies 2016, 9, 357. [CrossRef]

4. Raychiy, J.; Ming-Shiou, T.; Ching-Cherng, S. Novel optical lens design with a light scattering freeform inner surface for LED down light illumination. Opt. Express 2015, 23, 16715-16722.

5. Różowicz, A.; Leśko, M.; Wachta, H. The Technical Possibilities of Losses Reduction in the LED Optical Systems. In Proceedings of the 2016 IEEE Lighting Conference of the Visegrad Countries (LUMEN V4), Karpacz, Poland, 13-16 September 2016; Art. no. 978-1-5090-3305-8/16.

6. Zissis, G. Energy Consumption and Environmental and Economic Impact of Lighting: The Current Situation. In Handbook of Advanced Lighting Technology; Springer: Cham, Switzerland, 2016; pp. 1-13.

7. Leśko, M.; Różowicz, A.; Wachta, H.; Różowicz, S. Adaptive luminaire with variable luminous intensity distribution. Energies 2020, 13, 721. [CrossRef] 
8. Czyżewski, D. Comparison of luminance distribution on the lighting surface of power LEDs. Photonics Lett. Pol. 2019, 11, 118-120. [CrossRef]

9. Liu, L.; Keoleian, G.; Saitou, K. Replacement policy of residential lighting optimized for cost, energy, and greenhouse gas emissions. Environ. Res. Lett. 2017, 12, 114034. [CrossRef]

10. Barroso, A.; Dupuis, P.; Alonso, C.; Jammes, B.; Seguier, L.; Zissis, G. A Characterization Framework to Optimize LED Luminaire's Luminous Efficacy. In Proceedings of the 2015 IEEE Industry Applications Society Annual Meeting, Dallas, TX, USA, 18-22 October 2015; pp. 905-913.

11. Juntunen, E.; Tetri, E.; Tapaninen, O.; Yrjänä, S.; Kondratyev, V.; Sitomaniemi, A.; Siirtola, H.; Sarjanoja, E.; Aikio, J.; Heikkinen, V. A smart LED luminaire for energy savings in pedestrian road lighting. Lighting Res. Technol. 2015, 47, 103-115. [CrossRef]

12. Czyżewski, D. Research on Luminance Distributions of Chip-On-Board Light-Emitting Diodes. Crystals 2019, 9, 645. [CrossRef]

13. Różowicz, A.; Baran, K.; Wachta, H. Radiation studies of the illumination lighting luminaires with LED technology. In Proceedings of the 6th IEEE Lighting Conference of the Visegrad Group Countries, Karpacz, Poland, 13-16 September 2016; pp. 1-4.

14. Lasance, C.; Poppe, A. Thermal Management for LED Applications; Springer Science, Business Media: New York, NY, USA, 2014.

15. Yang, K.; Chung, C.; Tu, C.; Wong, C.; Yang, T.; Lee, M. Thermal spreading resistance characteristics of a high power light emitting diode module. Appl. Ther. Eng. 2014, 70, 361-368. [CrossRef]

16. Hui, S.; Li, S.; Tao, X.; Chen, W.; Ng, W. A novel passive offline LED driver with long lifetime. IEEE Trans. Power Electron. 2010, 25, 2665-2672. [CrossRef]

17. Hsu, H.-C.; Huang, Y.-C. Numerical simulation and experimental validation for the thermal analysis of a compact led recessed downlight with heat sink design. Appl. Sci. 2017, 7, 4. [CrossRef]

18. Ye, H.; Koh, S.W.; van Zeijl, H.W.; Gielen, S.; Zhang, G. A review of passive thermal management of LED module. J. Semicond. 2011, 32. [CrossRef]

19. Guo, Y.; Pan, K.; Ren, G.; Yuan, F. Research on LED Temperature Characteristic and Thermal Analysis at Low Temperatures. In Proceedings of the International Conference on Electronic Packaging Technology \& High Density Packaging, Guilin, China, 13-16 August 2012; pp. 1411-1415.

20. Scheepers, G.; Visser, J. Detailed Thermal Modeling of High Powered LEDs. In Proceedings of the 25th Annual IEEE Semiconductor Thermal Measurement and Management Symposium, San Jose, CA, USA, 15-19 March 2009; pp. 87-91.

21. Pounds, D.; Bonner, R. High heat flux heat pipes embedded in metal core printed circuit boards for LED thermal management. In Proceedings of the 14th Intersociety Conference on Thermal and Thermomechanical Phenomena in Electronic Systems (ITherm), Orlando, FL, USA, 27-30 May 2014; pp. 267-271.

22. Yurtseven, M.B.; Mete, S.; Onaygil, S. The effects of temperature and driving current on the key parameters of commercially available high-power white LEDs. Lighting Res. Technol. 2016, 48, 943-965. [CrossRef]

23. Baran, K.; Różowicz, A.; Wachta, H.; Różowicz, S.; Mazur, D. Thermal analysis of the factors influencing junction temperature of LED panel sources. Energies 2019, 12, 3941. [CrossRef]

24. Shen, Q.; Sun, D.; Xu, Y.; Jin, T.; Zhao, X. Orientation effects on natural convection heat dissipation of rectangular fin heat sinks mounted on LEDs. Int. J. Heat Mass Transf. 2014, 75, 462-469. [CrossRef]

25. Tzeng, S.; Jeng, T.; Wang, Y. The cooling design of a high-speed rotating axis with ribbed turbulators. IJETI $2013,3,38-48$.

26. Costa, V.; Lopes, A. Improved radial heat sink for led lamp cooling. Appl. Ther. Eng. 2014, 70, 131-138. [CrossRef]

27. Huang, Y.-S.; Luo, W.-C.; Wang, H.-C.; Feng, S.-W.; Kuo, C.-T.; Lu, C.-M. How smart LEDs lighting benefit color temperature and luminosity transformation. Energies 2017, 10, 518. [CrossRef]

28. Ron, H. Photo-Electro-Thermal Theory for LED Systems. In Basic Theory and Application; Cambridge University Press: Cambridge, UK, 2017.

29. Hyunjong, K.; Kyoung, J.; Yeonwon, L. Thermal Performance of Smart Heat Sinks for Cooling High Power LED Modules. In Proceedings of the 13th IEEE Intersociety Conference on Thermal and Thermomechanical Phenomena in Electronic Systems, San Diego, CA, USA, 30 May-1 June 2012.

30. Gupta, D.; Venkataraman, V.; Nimje, R. CFD\& Thermal Analysis of Heat Sink and its Application in CPU. Int. J. Emerg. Technol. Adv. Eng. 2014, 4, 198-202. 
31. Cao, J. Study on Three-imensional Numerical Simulation of the Influence of Fin Spacing on the Power of Heat Sink and Heat Dissipation. In Proceedings of the Asia-Pacific Power and Energy Engineering Conference, Wuhan, China, 25-28 March 2011.

32. Yieang, H.; Shengnan, S.; Hui, L.; Yunjie, G. Improved Thermal Design of Fin Heat Sink for High-Power LED Lamp Cooling. In Proceedings of the 17th International Conference on Electronic Packaging Technology, Wuhan, China, 16-19 August 2016; pp. 1069-1074.

33. Min, W.; Seung, W.; Yongchan, K. Optimal thermal design of a horizontal fin heat sink with a modified-opening model mounted on an LED module. Appl. Therm. Eng. 2015, 91, 105-115.

34. Teeba, N.; Anithambigai, P.; Dinash, K.; Mutharasu, D. Influence of the Heat Sink Orientation and Fins Arrangement on the Thermal Behavior of High Power LED. In Proceedings of the The 3rd Asia Symposium on Quality Electronic Design, Kuala Lumpur, Malaysia, 19-20 July 2011; pp. 21-24.

35. Rong, W.; Jung, W. Analyzing the structural designs and thermal performance of nonmetal lighting devices of LED bulbs. Int. J. Heat Mass Transf. 2016, 99, 750-761.

36. Mawby, P.A.; Igic, P.M.; Towers, M.S. Physically based compact device models for circuit modelling applications. Microelectr. J. 2001, 32, 433-447. [CrossRef]

37. Menozzi, R.; Cova, P.; Delmonte, N.; Giuliani, F.; Sozzi, G. Thermal and electrothermal modeling of components and systems: Review of the research at the University of Parma. Facta Univ. Ser. Electron. Energetics 2015, 28, 325-344. [CrossRef]

38. Janicki, M.; Torzewicz, T.; Ptak, P.; Raszkowski, T.; Samson, A.; Górecki, K. Parametric compact thermal models of power LEDs. Energies 2019, 12, 1724. [CrossRef]

39. Poppe, A. Simulation of LED based luminaires by using multi-domain compact models of LEDs and compact thermal models of their thermal environment. Microelectron. Reliab. 2017, 72, 65-74. [CrossRef]

40. Chen, H.; Lin, S.; Xiong, C. Analysis and modeling of thermal effect and optical characteristic of LED systems with parallel plate-fin heatsink. IEEE Photonics J. 2017, 9. [CrossRef]

41. Cuntala, J.; Kondelova, A.; Hock, O.; Pridala, M. Electro-Thermal Modeling of Power LED Using.COMSOL Environment. In Proceedings of the 11th International Conference ELEKTRO, Strbske Pleso, Slovakia, 16-18 May 2016; pp. 127-130.

42. GL Opti Spheres. Available online: http://www.gloptic.com/wpcontent/uploads/2018/08/200931_TechnicalDatasheet_SPHEREs.pdf (accessed on 3 January 2020).

43. GL Spectis 6,0. Available online: http://www.gloptic.com/wp-content/uploads/2018/08/200930_TechnicalDatasheet_SPECTIS-6-0.pdf (accessed on 3 January 2020).

44. 5305 TECSource Arroy Instruments. Available online: http://www.arroyoinstruments.com/products/5305\# tabs (accessed on 3 January 2020).

45. Houser, K.; Mistrick, K.; Steffy, G.; Dlaura, D. The Lighting Handbook: Reference and Application, 10th ed.; Illuminating Engineering Society of North America (IES): New York, NY, USA, 2011.

46. Liu, S.; Luo, X. LED Packaging for Lighting Applications: Design, Manufacturing and Testing; John Wiley \& Sons Pte Ltd.: Singapore, 2011.

47. Min, S. Thermal Analysis of High Power LED Arrays. Ph.D. Thesis, Georgia Institute of Technology, Atlanta, GA, USA, 2009.

48. Palisoc, A.; Lee, C. Thermal-properties of the multilayer infinite-plate structure. J. Appl. Phys. 1988, 64, 410-415. [CrossRef]

49. Masana, F. A new approach to the dynamic thermal modelling of semiconductor packages. Microelectron. Reliab. 2001, 41, 901-912. [CrossRef]

50. Muzychka, Y.; Culham, R.; Yovanovich, M. Thermal spreading resistance of eccentric heat sources on rectangular flux channels. ASME J. Electron. Packag. 2003, 125, 178-185. [CrossRef]

51. FloEFD. Technical Reference, Software Version 16, Mentor Graphics; Mentor Graphics Corporation: Wilsonville, OR, USA, 2016.

52. Chein, R.; Chen, J. Numerical study of the inlet/outlet arrangement effect on microchannel heat sink performance. Int. J. Ther. Sci. 2009, 48, 1627-1638. [CrossRef]

53. Della Torre, A.; Motenegro, G.; Onorati, A.; Khadilkar, S.; Icarelli, R. Multi-scale CFD modeling of plate heat exchangers including $\mathrm{O}$ set-strip fins and Dimple-Type Turbulators for automotive applications. Energies 2019, 12, 2965. [CrossRef] 
54. FloEFD Engineering Database. Available online: https://www.mentor.com/products/mechanical/floefd/ (accessed on 3 January 2020).

55. Torzewicz, T.; Baran, K.; Raszkowski, T.; Samson, A.; Wachta, H.; Napieralski, A. Compact Thermal Modeling of Power LED Light Source. In Proceedings of the IEEE 30th International Conference on Microelectronics (MIEL), Nis, Serbia, 9-11 October 2017; pp. 157-160.

56. JEDEC STANDARD. Transient Dual Interface Test Method for the Measurement of the Thermal Resistance Junction-to-Case of Semiconductor Devices with Heat Flow through a Single Path; JESD51-14; JEDEC Solid State Technology Association: Arlington, VA, USA, 2010.

57. Baran, K.; Wachta, H.; Leśko, M.; Różowicz, A. Research on thermal resistance Rthj-c of high power semiconductor light sources. In Proceedings of the 15th Conference on Computational Technologies in Engineering, AIP Conference Proceedings 2078, Mikołajki, Poland, 16-19 October 2018; p. 020047.

58. L200-TC Labfacility 8-Channel Laboratory Temperature Monitor. Available online: https://www.labfacility. com/media/productattach/d/a/datasheet_-_1200.pdf (accessed on 3 January 2020).

59. Konica Minolta Spectroradiometer CS-2000. Available online: https://www.konicaminolta.com/instruments/ download/instruction_manual/display/pdf/cs-2000-2002a_instruction_eng.pdf (accessed on 3 January 2020).

(C) 2020 by the authors. Licensee MDPI, Basel, Switzerland. This article is an open access article distributed under the terms and conditions of the Creative Commons Attribution (CC BY) license (http://creativecommons.org/licenses/by/4.0/). 